\title{
Tecnologias Digitais e Metodologias Ativas na Formação Continuada de Professores: uma experiência de Sala de Aula Invertida no $9^{\circ}$ ano do Ensino Fundamental
}

João Manoel Magalhães Cruz - SEMED Itaperuna/RJ - jmmagcruz@gmail.com Arilise Moraes de Almeida Lopes - IFFluminense - ariliselopes@gmail.com Analice de Oliveira Martins - IFFluminense - analice.martins@ terra.com.br

Resumo: Formação Continuada de Professores é uma área que se destaca entre os temas que discutem Educação, com inegável importância da participação do docente no processo ensino-aprendizagem de seus alunos. Neste contexto foi desenvolvido um curso de formação continuada para professores de Língua Portuguesa e Matemática do $9^{\circ}$ ano do Ensino Fundamental e da Fase IX da Educação de Jovens e Adultos oferecida na plataforma Schoology. Este artigo tem por objetivo apresentar a proposta de um curso de formação continuada para professores da rede municipal de Itaperuna (RJ) com ênfase em Metodologias Ativas e a aplicação por uma docente de Matemática participante do curso, de uma Sequência Didática com conteúdos de estatística básica que foi desenvolvida durante a formação continuada, utilizando a metodologia da Sala de Aula Invertida. A pesquisa é descrita como qualitativa e os instrumentos de coleta de dados foram questionário e observação. $\mathrm{O}$ curso foi avaliado de modo positivo pelos professores, que consideram necessário o aperfeiçoamento da prática pedagógica. A docente que aplicou a metodologia Sala de Aula Invertida também descreveu ter sido excelente, sendo o professor um facilitador desse processo. Conclui-se que a qualificação com metodologias ativas tende a produzir bons resultados em sala de aula.

Palavras-chave: formação continuada de professores, metodologias ativas, sala de aula invertida, Schoology.

\section{Digital Technologies and Active Methodologies in Continued Teacher Training: a room experience of Flipped Classroom in the $9^{\text {th }}$ grade of Elementary School}

Abstract: Teachers Continued Formation is an area that stands out among the themes that discuss Education, with undeniable importance of teacher participation in the teaching-learning process of its students. In this context, a continuing education course was developed for Portuguese Language and Mathematics teachers from the 9th grade of midlle school and Phase IX of young people and Adult Education offered on the Schoology platform. This article aims to present the proposal of a continuing training course offered to teachers of a district schools network of Itaperuna (RJ) with emphasis on Active Methodologies and the application by a Mathematics teacher participating in the course of a Didactic Sequence with contents of basic statistics that was developed during continuing formation, using the Inverted Classroom methodology. The research is described as qualitative and the instruments of data collection were questionnaire and observation. The course was evaluated positively by the teachers, who consider it necessary to improve the pedagogical practice. The teacher who applied the Classroom methodology also described being excellent and the teacher a facilitator of this process. We conclude that the qualification with active methodologies and digital technologies tends to produce good results in the classroom.

Keywords: continued teacher training, active methodologies, flipped classroom, Schoology 


\section{Introdução}

Contemporaneamente, em educação, busca-se na Formação Continuada de Professores (FCP) parcelas de mudança e inovação em virtude da clara necessidade das teorias e práticas de ensino, dos planejamentos, estratégias e meios de articulação estarem alinhados às novas perspectivas sociais vigentes (IMBERNÓN, 2010). A FCP é uma ação importante quando se assume o desafio de qualificar o processo de ensino e aprendizagem (SANTAROSA; CONFORTO, 2010).

Neste contexto foi concebido um curso de FCP com ênfase em Metodologias Ativas (MA) oferecido na plataforma Schoology, para professores de Língua Portuguesa e Matemática do $9^{\circ}$ ano do Ensino Fundamental (EF) que atuam no município de Itaperuna, estado do RJ, rede na qual o primeiro autor atua como gestor de escola, de forma a contribuir para mudanças na prática pedagógica desses professores.

A escolha pelo EF foi definida tendo em vista a solicitação da secretaria de educação do município em estimular melhorias na prática pedagógica dos docentes que atuam no ano final da referida etapa de ensino, cujos alunos são conceituados por meio da avaliação externa denominada Prova Brasil, de modo a constituir o Índice de Desenvolvimento da Educação Básica (IDEB), que determina os avanços da educação em âmbito municipal, estadual e federal (INEP, 2017).

A FCP foi organizada de modo flexível e dinâmica, para atender à demanda profissional dos professores que trabalham com os conteúdos da Prova Brasil e que têm justificado uma necessidade de novas práticas na abordagem desses conteúdos para a preparação de seus alunos (KENSKI, 2015).

Assim, o presente artigo tem por objetivo apresentar a proposta de um curso de formação continuada oferecido a professores de uma rede municipal com ênfase em MA e a aplicação por uma professora de Matemática participante do curso, de uma Sequência Didática (SD) com conteúdos de estatística básica que foi desenvolvida durante a FCP, utilizando a metodologia de Sala de Aula Invertida.

Bacich e Morán (2018) afirmam que a FCP é a peça-chave para a melhoria das escolas e para uma produtiva reforma curricular. Deste modo, ao oferecer um curso de FCP, espera-se que a utilização de novas abordagens pedagógicas e metodologias mais adequadas à realidade dos alunos reflitam em melhorias na sala de aula.

Este artigo estrutura-se em cinco seções. Além desta introdução, na seção dois, apresenta-se uma breve revisão bibliográfica sobre metodologias ativas e a Sala de Aula Invertida. Na seção três, descreve-se a metodologia adotada nesta pesquisa. Na seção quatro, descreve-se o curso desenvolvido na plataforma Schoology. Na seção cinco, discutem-se os resultados do curso oferecido e a aplicação de uma SD planejada com base na formação advinda do curso, por uma professora de Matemática e, finalizando, na seção seis, são feitas considerações sobre a pesquisa realizada.

\section{Metodologias Ativas: Sala de Aula Invertida (SAI)}

As Metodologias Ativas (MA) promovem a aprendizagem por meio da construção dos conhecimentos, observando a experiência dos alunos em situações reais ou simuladas, propondo soluções para os desafios do cotidiano (BERBEL, 2011). Nas MA, o aprendizado dos alunos ocorre a partir de problemas e contextos reais durante sua formação, sendo estes vivenciados depois na vida profissional (MORÁN, 2015).

Neste contexto, a MA de Sala de Aula Invertida (SAI) é uma das formas de ensino híbrido que propõe a construção dos conhecimentos pelos alunos a partir da alternância entre atividades presenciais e atividades realizadas on-line (geralmente a partir de um Ambiente Virtual de Aprendizagem - AVA). 
Cabe ressaltar que a ausência do recurso tecnológico AVA não é impedimento para aplicação da SAI. Constitui-se um potencializador, mas não é requisito (BERGMANN; SAMS, 2018).

Nesse sentido, Schmitz (2016) define três momentos para elaboração de um planejamento de aula por meio da SAI: (I) antes da aula, momento no qual o professor elabora o conteúdo para o aluno estudar antecipadamente; (II) durante a aula, quando o aluno desenvolve atividades práticas e submete dúvidas ao professor e (III), depois da aula, no fechamento do conteúdo proposto e avaliando a necessidade de novos estudos sobre o conteúdo abordado.

Sota (2016) apresenta alguns benefícios que possibilitam mudanças nos processos de ensino e aprendizagem: (i) oportuniza colaboração e processos de interação entre os alunos; (ii) o aluno se torna responsável pelo seu aprendizado; (iii) promove uma aprendizagem personalizada e (iv) tanto o professor como o aluno têm um feedback imediato do trabalho que realizaram.

Visualiza-se com a adoção desta metodologia a mudança de postura do professor, que atua como facilitador do processo de ensino e aprendizagem em função de um aluno ativo na elaboração de seus conhecimentos (BALDEZ; DIESEL; MARTINS, 2017).

\section{Procedimentos Metodológicos}

Para este trabalho traz-se a concepção do curso de FCP com ênfase em MA e a aplicação da SAI por uma professora de Matemática, que participou do curso, proposta por meio de uma Sequência Didática (SD) com conteúdos de estatística básica que foi desenvolvida durante a FCP. Realizou-se uma pesquisa qualitativa, que, de acordo com Oliveira (2009), é o tipo de pesquisa em que são analisadas a realidade em um processo de reflexão que utiliza métodos e técnicas para a compreensão do objeto de estudo e sua relação com o contexto sócio-histórico no qual se está inserido. O curso de FCP teve como público-alvo 14 professores, sendo sete de Língua Portuguesa, cinco de Matemática do Ensino Regular, um de Língua Portuguesa e um de Matemática da Educação de Jovens e Adultos de uma rede municipal de ensino, e estes foram nomeados por P1, P2, P3,... P14, buscando manter o sigilo destes professores e definido por $\mathrm{P}$, o pesquisador e primeiro autor deste trabalho.

Como instrumentos de coleta de dados, foram adotados a observação e três questionários, sendo um antes da capacitação, o segundo ao término do curso oferecido e um terceiro respondido neste trabalho pela professora que aplicou a metodologia de SAI com seus alunos.

O questionário pré-capacitação foi elaborado com base nos descritores da Matriz de Referência da Prova Brasil inicial e teve por objetivo a obtenção de um diagnóstico que direcionasse a FCP nos conteúdos e temas a serem trabalhados, levantando as principais dificuldades de aprendizagem notadas pelos professores da rede municipal nos conteúdos/descritores de Língua Portuguesa e Matemática e levantar dados sobre o uso das Tecnologias Digitais (TD) pelos mesmos.

O questionário aplicado ao final do curso buscou levantar as contribuições que o curso promoveu para mudanças na prática pedagógica dos professores. Já o questionário empregado após a aplicação da SD em sala de aula buscou levantar dados sobre os processos de ensino e aprendizagem provenientes da adoção da metodologia de SAI.

Já a observação foi escolhida por ser um eficaz recurso para o registro imediato das percepções do pesquisador durante a aplicação das SD junto aos professores cursistas e seus alunos (ARAÚJO et al. 2013). 


\section{Concepção do curso de Formação Continuada de Professores na plataforma Schoology}

O curso foi organizado pelos autores deste artigo de modo semipresencial utilizando a Plataforma Schoology e aberto a 20 professores da etapa final do EF (Regular e EJA). A FCP foi intitulada "Tecnologias Digitais de Informação e Comunicação (TDIC) e Metodologias Ativas (MA): Uma proposta para o Ensino Fundamental”'. O Schoology foi escolhido por não depender de um servidor para hospedagem dos materiais e também pela familiaridade adquirida pelo primeiro autor do artigo em disciplinas ofertadas no mestrado do qual é aluno, tendo em vista que, no período de um ano em que teve contato e o utilizou, a plataforma demonstrou estabilidade, eficiência e usabilidade muito positivas, o que influenciou na escolha do ambiente.

O curso híbrido de FCP pretendeu oferecer aos professores conhecimentos sobre MA, apresentando SAI e Aprendizagem por Pares (APP), com a duração de 80 horas, divididos em quatro unidades, com três encontros presenciais e atividades à distância.

Os professores formaram grupos para a elaboração de uma SD abordando SAI e outra SD abordando APP de modo a aplicarem com seus alunos em sala de aula. O curso foi planejado (Figura 1) possuindo a seguinte estrutura:

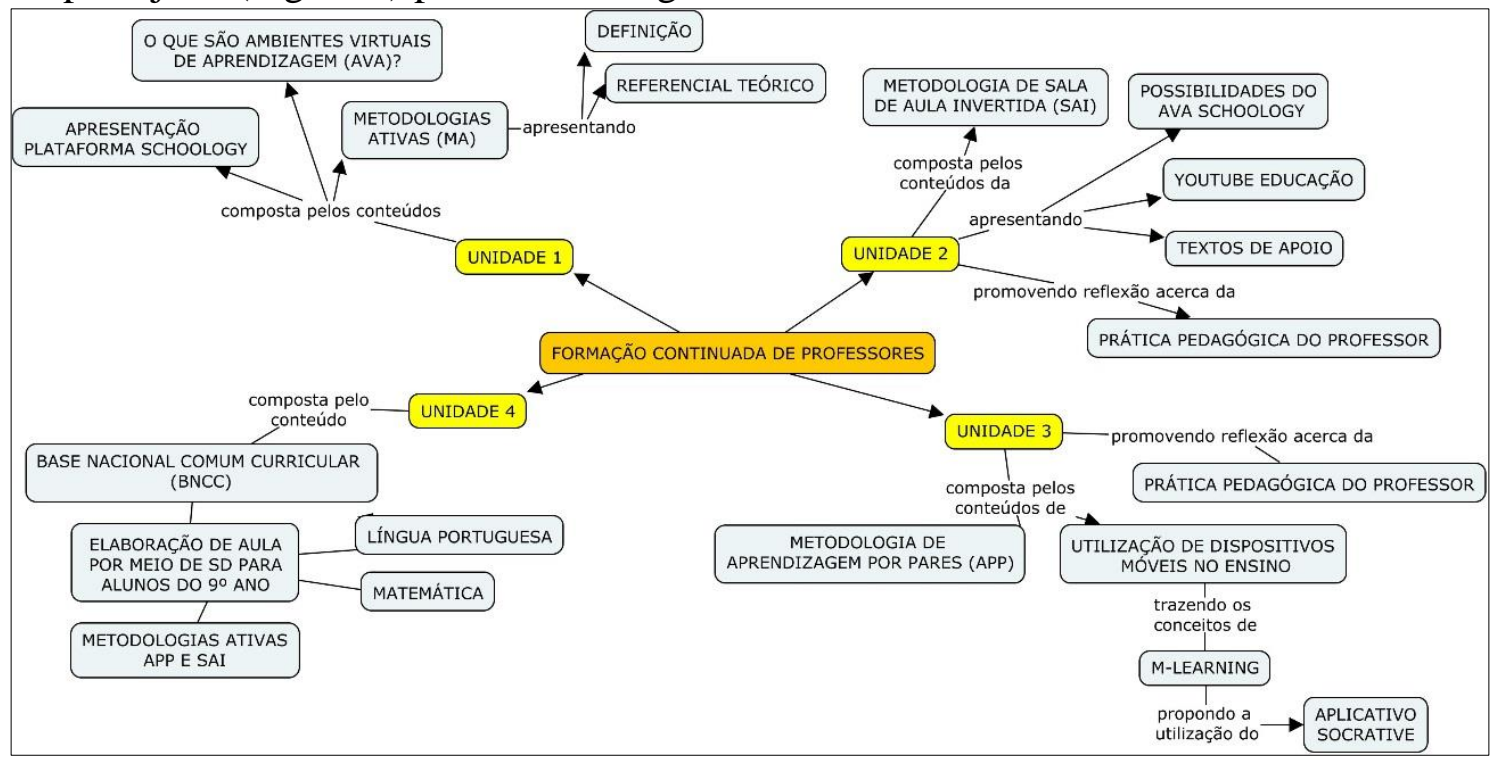

Figura 1- Estrutura do curso de FCP.

Fonte: Elaboração própria.

As Unidades 3 e 4 não são objetos de estudo neste artigo, em virtude de um estudo em finalização do Mestrado do qual o primeiro autor é aluno e do recorte e delimitação proposto neste artigo. Para este trabalho, apresentam-se resultados da concepção do curso de FCP com a descrição das Unidades 1 e 2 e a adoção da SAI por uma professora de Matemática do $9^{\circ}$ ano do Ensino Fundamental de uma rede pública municipal.

\section{Resultados e discussão}

\subsection{O curso de Formação Continuada de Professores (FCP)}

As inscrições dos professores na plataforma Schoology ocorreram ao final da elaboração do curso, no mês de setembro de 2018, na secretaria de educação do município. A cada cursista foi apresentada a plataforma. Analisando os dados do questionário pré-capacitação, observou-se, enquanto perfil tecnológico dos professores, que estes utilizam computador com projetor multimídia para exibição de slides e vídeos em suas aulas, utilizam smarthphone e se comunicam por Whatsapp com os alunos. 
Para que os cursistas pudessem se preparar para o primeiro encontro presencial, que teve como propósito as Unidades 1 e 2 , na data da inscrição, foram liberados para leitura dos professores na plataforma Schoology, a Unidade1, com dois textos geradores: "Mudando a educação com metodologias ativas", de autoria de José Morán e "Os princípios das metodologias ativas de ensino: uma abordagem teórica", das autoras Aline Diesel, Alda Leila Santos Baldez e Silvana Neumann Martins.

A Unidade 1 foi elaborada oferecendo aos professores cursistas artigos, links a páginas web e o recurso fórum da plataforma Schoology, de modo a inserir os professores na temática das discussões a serem propostas pela FCP.

O primeiro encontro presencial ocorreu em outubro de 2018, em um instituto federal, com início às 18 horas no laboratório de recursos tecnológicos. A aula foi iniciada com boas-vindas aos professores cursistas e foram levantados alguns questionamentos sobre o interesse dos professores nos textos disponibilizados para a leitura na Unidade 1, momento em que eles tiveram a oportunidade de refletir e discutir sobre MA e suas inquietações sobre suas práticas pedagógicas, enquanto professores regentes em escolas públicas da rede municipal. Muitos não tinham conhecimento dessa metodologia e já neste momento, observaram-se desejos de mudanças em suas práticas.

Passou-se para a Unidade 2 apresentando no Schoology os recursos disponíveis: (i) textos de apoio pesquisados e disponibilizados abordando a SAI, (ii) vídeos do YouTube Educação e (iii) uma atividade propondo a elaboração de uma SD a ser realizada em grupo. Foi colocado aos professores que, para facilitar a construção da SD, havia sido disponibilizado um modelo de SD na plataforma com os seguintes tópicos facilitadores: (1) Caracterização da SD contendo: título, introdução e justificativa, público/ano de escolaridade, disciplina, número de aulas pretendido, conteúdos e descritores utilizados e objetivo geral; (2) Momento antes da aula; (3) Momento em sala de aula e (4) Momento após sala de aula (feedback) contendo: problematização, objetivos específicos, recursos e materiais disponibilizados, descrição procedimental da etapa, estratégia de avaliação adotada e tempo estimado de estudo do aluno fundamentado em (SCHMITZ, 2016).

Após conhecerem os recursos, foi feita uma apresentação sobre a SAI, disponível na plataforma e ao final foi aberta a palavra aos professores para perguntas e considerações. Em seguida, foi exibido o vídeo disponível no YouTube "A SAI na prática" por meio do link https://www.youtube.com/watch?v=GJb qFAMWuXE. O vídeo trouxe importantes considerações sobre a adoção da SAI na prática de ensino do professor.

No YouTube Educação, canal do YouTube com conteúdo educacional vasto, avaliado por pares especialistas de diversas áreas do conhecimento, que constitui um grande facilitador ao trabalho do professor ao adotar a SAI, foram mostrados vídeos, videoaulas, tutoriais e outros materiais nele disponibilizados que os professores poderiam utilizar com seus alunos na adoção da metodologia. Foram ainda apresentados por uma colaboradora um exemplo de SD e uma experiência de sua aplicação em sala de aula. Os professores fizeram perguntas e esclareceram suas dúvidas sobre o assunto. $\mathrm{O}$ exemplo foi disponibilizado na plataforma.

Após este momento, foi proposto que os professores se reunissem em grupos por áreas afins para iniciarem a elaboração de uma SD a ser aplicada em sala de aula pelos mesmos e determinou-se a data para envio da atividade. Foi também criado, por sugestão dos cursistas, um grupo de WhatsApp para facilitar a troca de informações entre os pares e os autores. Os professores iniciaram o desenvolvimento da SD no curso e deram continuidade à distância, com interações de suas dúvidas pelo WhatsApp. Algumas dúvidas se mostraram relevantes:

P12: <É necessário ou obrigatório utilizar uma AVA para implantar a SAI?> P: Nos estudos de Bergmann e Sams, o autor coloca que a SAI não depende de um AVA, mas que com a utilização deste, muitas possibilidades são abertas aos 
professores. Em caso de escolas sem laboratório, pode-se utilizar materiais pedagógicos impressos elaborados pelo professor para o estudo individualizado do aluno no momento anterior à aula presencial.

P10: <O que pode ser feito pelo professor quando o aluno não estuda no momento anterior à aula?>

P: O próprio vídeo comentou acerca da solução desta dificuldade. O professor pode reunir os alunos que não estudaram em um grupo para que o façam em sala de aula, enquanto media a problematização aos que já leram os materiais disponibilizados em casa.

P7: <Como utilizar o livro didático na SAI?>

P: Ficou entendido que o livro não é deixado de lado na SAI. A abordagem de utilização que muda. A teoria fica em maior parte para casa e em sala, desafios e resolução de problemas.

Foram também discutidos entre os professores e o pesquisador o tempo dos vídeos disponibilizados e a extensão das leituras e tarefas propostas para antes da aula presencial. Buscou-se mostrar aos professores a necessidade de clareza e objetividade na proposição das atividades. De maneira geral, observou-se que os professores durante o curso mostraram-se receptivos aos conhecimentos oferecidos abordando SAI. O encontro promoveu momentos de reflexão sobre a prática pedagógica no sentido de propor melhorias no processo educativo incluindo a SAI, de superar a indisciplina e a falta de participação dos estudantes, que, segundo os professores, são muitos comuns nesse ano de escolaridade.

No questionário de avaliação do curso aplicado, destacaram-se duas falas que corroboram com o elucidado acima:

P10<A metodologia de Sala de Aula Invertida contribuiu grandemente para minha formação, possibilitando-me um meio de melhorar a minha prática e despertar mais interesse do aluno para o conteúdo ministrado. Uma maneira mais atual e dinâmica, onde pude unir algo que interessa aos meus alunos com o conteúdo de matemática>.

$\mathrm{P} 6<$ Eu vejo que o processo de ensino e aprendizagem será mais facilitado utilizando a Sala de Aula Invertida. Acredito que os alunos que se apropriam do conhecimento em casa antes da aula se sentem mais seguros e estimulados a desafiá-los com questões onde requer deles mais concentração e esforço...>.

\subsection{Aplicação da Sequência Didática (SD) com a metodologia SAI}

A aplicação da SD desenvolvida durante o curso, com a metodologia SAI, ocorreu no laboratório de informática da escola e em sua sala de aula, no mês de abril de 2019 , com 14 alunos do $9^{\circ}$ ano do EF. Contou com a participação de uma professora de Matemática, que se nomeia por P10, participante do curso e do pesquisador na condição de observador. A professora tem autonomia para usar TD em suas aulas e, neste sentido, foram utilizadas como recursos tecnológicos: notebook, projetor e caixa de som amplificada. Também optou por fazer uso da plataforma Khan Academy, que já conhecia, por conta da variedade de materiais oferecidos para a área de Matemática e os recursos interativos que a plataforma dispõe de modo a promover construção dos conhecimentos de quem a utiliza, para elaborar a SD.

O primeiro encontro com os alunos ocorreu no dia quatro de abril de 2019. Ao se apropriar dos conhecimentos adquiridos no curso, a professora inicialmente solicitou que os alunos disponibilizassem seus e-mails para que ela pudesse fazer a enturmação dos mesmos no Khan Academy.

Foi apresentada aos alunos a plataforma Khan Academy, que seria utilizada para estudarem os descritores D25 e D33 da Matriz de Referência do $9^{\circ}$ ano do EF, a qual abordava a introdução a estatística, tema desenvolvido na SD com a aplicação da metodologia SAI. Explicou aos alunos que deveriam estudar em casa um material 
impresso elaborado por ela, com duas questões para serem respondidas antes da aula presencial. Enviaria ainda, por e-mail, os links de dois vídeos introdutórios que deveriam acessar na unidade "Introdução à estatística: média, mediana e moda" da plataforma Khan Academy e que serviriam para aprofundar conhecimentos na resolução das atividades propostas na unidade, de modo a testar os conhecimentos obtidos.

O segundo momento, na aula seguinte, que ocorreu no laboratório da instituição, era para ser a hora em que os alunos trazem dúvidas, discutem, colaboram entre si. Os alunos já deveriam ter estudado previamente o material disponibilizado em relação à metodologia adotada, caracterizado pela aprendizagem ativa, dos 14 alunos cadastrados no Khan Academy. Neste momento, percebeu-se que cinco alunos não haviam acessado a plataforma, nem respondido às questões propostas. Ao perguntar a estes alunos o porquê de não realizarem as atividades propostas, os mesmos argumentaram não terem o hábito de estudar com antecedência ou acessarem o AVA para estudar por meio do mesmo. Pode-se, observando a situação em sala, inferir talvez sobre a imaturidade de alguns alunos em estudar a distância.

De modo a contornar a situação indesejável, P10 ajudou os cinco alunos no acesso à plataforma e pediu que, como não tinham realizado a atividade proposta em casa, assistissem aos vídeos solicitados em seus computadores, disponibilizando aproximadamente 20 minutos para esta realização. Pediu para os alunos que realizaram as tarefas com sucesso e já estavam familiarizados contribuíssem ajudando aos colegas. Neste momento, alguns alunos pediram que a professora passasse para todos os dois vídeos solicitados para o estudo antes da aula. A mesma assim o fez e, após todos terem assistido o vídeo, a professora retomou a discussão sobre as duas questões deixadas para casa, antes da aula presencial. Os nove alunos que estudaram o conteúdo antes da aula, responderam com facilidade as questões propostas que exploravam média e mediana, com exceção de um item da questão dois, que perguntava acerca de "como fazer o cálculo da mediana em um conjunto de números pares".

Pensando em inserir os alunos que não cumpriram as tarefas do momento anterior à aula, a professora promoveu a seguinte ação: chamou à frente da sala um número ímpar de alunos e solicitou que eles se organizassem de forma crescente de altura, ou seja, do menor para o maior (Figura 2).

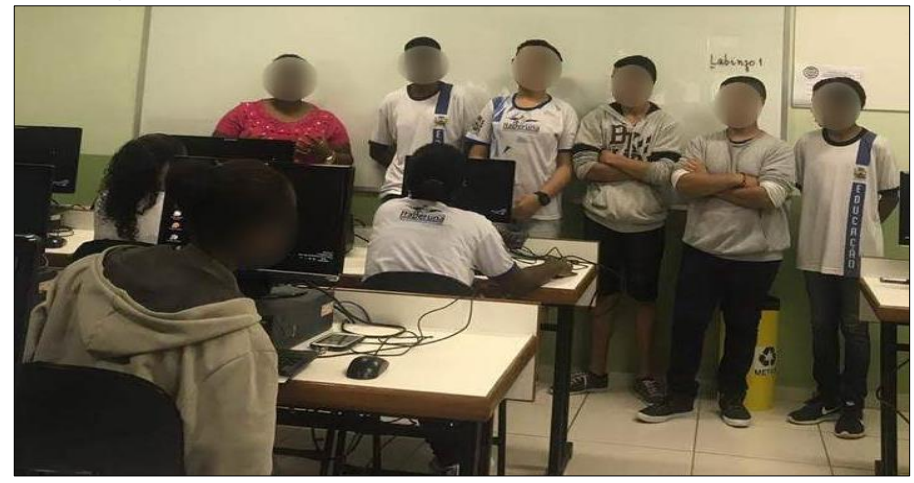

Figura 2 - Professora e cinco alunos em sala de aula. Fonte: Elaboração própria.

A professora perguntou aos que estavam sentados:

\section{P: Qual a altura mediana desse grupo de alunos?}

A grande maioria respondeu que seria o aluno " $x$ " que estava no meio.

Diante desta resposta a professora solicitou que estes alunos se sentassem e repetiu a atividade convidando um número par de alunos para irem à frente da classe e novamente 
perguntou ao restante da classe qual seria a altura mediana desse grupo de alunos. Neste momento, a professora percebeu que todos os alunos chegaram a um mesmo ponto de dúvida. Alguns alunos ficaram confusos, sendo que uma chegou a dizer que não teria altura mediana, pois não dava para saber com um número par de alunos. A professora prosseguiu indagando-lhes onde "mais ou menos" estaria a mediana do grupo de seis elementos.

A maioria respondeu que a altura mediana se encontrava entre os dois estudantes mais próximos do meio. A professora comentou que estavam no caminho certo, pois quando trouxe o exemplo com números ímpares, eles responderam corretamente e, nessa ocasião, tentou levar os alunos a deduzirem uma solução matemática do problema. Percebeu-se que os alunos tinham dificuldade em apresentar uma expressão matemática e, nesse momento, a professora apresentou a solução mostrando que a mediana, nesses casos, é obtida pela média entre os dois elementos mais próximos do meio.

Terminado este momento de exploração da dificuldade dos alunos em relação à atividade proposta fora da sala de aula, os alunos foram direcionados para a sala ao lado do laboratório, que possui uma organização móvel favorável para o trabalho em equipes e proposta a realização de uma atividade impressa com os conteúdos de estatística básica, média, moda e mediana, visando ao aprofundamento dos conhecimentos dos alunos, a partir dos vídeos propostos e das duas questões elaboradas. O pesquisador auxiliou a professora com a leitura da atividade proposta e a professora com a explicação da mesma, e no atendimento às dúvidas das equipes (Figura 3 ).

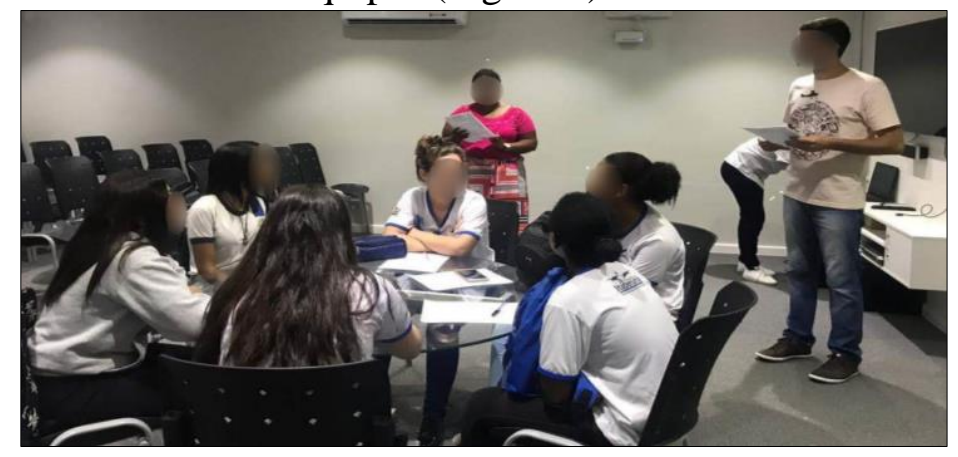

Figura 3 - Pesquisador e professor mediando atividade com os alunos. Fonte: Elaboração própria.

Depois de um tempo, a professora pediu que cada equipe fosse à frente da turma para contribuírem na correção da atividade. A professora procurava entender o raciocínio dos alunos, fazendo inserções, mediando os conhecimentos com a turma e com a equipe que apresentava. Ao final deste momento, aproximava-se o término da aula e, para obter um feedback avaliativo da experiência realizada, a professora deixou como atividade de casa um levantamento estatístico para pesquisa entre os alunos com os seguintes temas, um para cada grupo: 1) Qual aplicativo você mais utiliza no celular? 2) Por quanto tempo você utiliza a internet diariamente? 3) Qual o jogo que você mais utiliza no celular? Determinou-se que os alunos realizassem uma pesquisa com 30 alunos da escola, na faixa etária de 10 a 16 anos de idade, e organizassem os dados obtidos de modo a obterem as medidas de tendência central (média, mediana e moda) referente à pesquisa. Foi solicitado que também fosse construído um gráfico de barras para demonstrar a pesquisa obtida aos colegas.

Após o término de aplicação da SD, o pesquisador solicitou que a professora respondesse a um questionário de avaliação da prática pedagógica. O questionário trouxe dados bastante relevantes que possibilitaram, a partir da fala da professora, inferir que o 
curso promoveu mudanças em sua prática pedagógica e na aprendizagem de seus alunos, conforme extratos das falas a seguir:

P: Como você, professor, analisa o processo de ensino e aprendizagem fundamentada na Sala de Aula Invertida a ser aplicado em sua sala de aula?

$\mathrm{P} 10<$ Pude observar que o conhecimento adquirido é bem mais consolidado, pois eles revivem em sua memória o que aprenderam anteriormente e aplicam para resolver algo mais complexo. Ficam abertos a discussões, sem deixar o medo do "não sei" atrapalhar o seu raciocínio $>$.

P:Como você avalia a sua utilização da metodologia de Sala de Aula Invertida?

$\mathrm{P} 10<$ Excelente, obtive resultado melhor do que eu esperava>.

P: Quanto à aprendizagem dos alunos com relação ao conteúdo proposto, como você classifica a aprendizagem da turma?

P10<Muito satisfatória. Observei que eles não só entenderam, mas adquiriram o conhecimento $>$.

P: O estímulo à proposta de ensino por meio da teoria de Sala de Aula Invertida, proporcionou a melhoria da abordagem de conteúdos em sala de aula? De que maneira?

$\mathrm{P} 10<$ Sim. Porque entendi que quando disponibilizamos meios para que os alunos tenham acesso ao que será ou está sendo ensinando, faz com que ele ser torne mais autônomo e não veja somente no professor a maneira de adquirir o conhecimento. Ele passa a entender que o conhecimento está nas mais dele, e o professor só está facilitando esse processo >.

P: Os recursos tecnológicos adotados facilitaram o processo de compreensão do conteúdo?

P10<Facilitaram muito, porque eles têm maior atenção quando se trata de usar um computador ou celular, ou mesmo um projetor. Só o fato de não estarem totalmente utilizando apenas caderno, lápis e caneta e ter outros meios de adquirir o conhecimento já faz com que a aula fique mais atrativa e os alunos mais motivados para o aprendizado $>$.

Cabe ressaltar que o questionário respondido não trouxe apenas pontos positivos. A professora ressaltou, como dificuldades para utilização da metodologia, a falta de compromisso de alguns alunos em não estudar o material solicitado antes da aula presencial, o que, na situação em sala de aula, fez com que a professora fizesse adaptações na SD proposta. Explicou que não é fácil colocar os alunos para estudarem sozinhos, e afirmou que "É caminhando que se faz o caminhar".

P: No momento anterior à aula, os alunos participaram estudando e fazendo as tarefas propostas? Como se deu o autodidatismo dos alunos? $\mathrm{P} 10<$ Alguns alunos não estavam dispostos a realizar as tarefas, uns com pouca possibilidade e outros por falta de interesse. Mas de modo que fui argumentando, insistindo e cobrando que fizessem, consegui que parte realizassem as tarefas, alguns fizeram toda, e outros apenas assistiram algum dos vídeos>.

Outra dificuldade foi para acessar o material on-line, como falta de internet, computador em casa, entre outros. Destacou que reconhece que ainda precisa avançar, mas que reconhece válido o esforço por melhorias e que, sem este esforço, fica difícil se manter lecionando, pois os alunos solicitam sempre inovações e aulas diferenciadas.

\section{Considerações Finais}

Foi possível nesse artigo abordar a concepção de um curso de formação continuada propondo aos professores trabalharem em suas escolas com a metodologia SAI. Entende-se que, ao possibilitar qualificação profissional, esta pode interferir de forma positiva em sua prática docente, reestruturando práticas tradicionais $\mathrm{e}$ possibilitando melhorias no processo de ensino e aprendizagem. 
As mudanças em práticas tradicionais de ensino são graduais e progressivas. Os avanços começam em pequenas ações práticas e a proposta do curso de FCP foi possibilitar aos professores uma reflexão sobre sua prática docente ao desenvolverem uma SD e aplicarem em sua sala de aula.

Com relação ao estudo prévio não realizado por alguns alunos, como o planejado inicialmente, foi mencionado por eles que não tinham o hábito de estudar antes da aula ou estudar por meio de uma plataforma virtual. Ressalta-se que, ao propor uma metodologia não antes aplicada, há necessidade de um tempo para se adaptar, sendo compreensível este resultado na primeira experiência aplicada.

Conclui-se neste artigo que o curso proposto e a implantação da SAI em uma turma de $9^{\circ}$ ano do EF na disciplina de Matemática de uma escola pública municipal trouxe resultados bem positivos, na medida que contribuiu para melhoria da prática pedagógica da professora quando coloca que o resultado foi melhor do que esperava. Essa proposta deverá ser ampliada para mais professores da Secretaria Municipal de Educação (SEMED) do município onde ocorreu o curso, e estes professores participantes serão replicadores em suas escolas.

\section{Referências}

ARAÚJO, L. F. S. et al. Diário de pesquisa e suas potencialidades na pesquisa qualitativa em saúde. Revista Brasileira Pesquisa Saúde, p. 53-61, jul./set. 2013. BACICH, L.; MORÁN, J.M. Metodologias ativas para uma educação inovadora: uma abordagem teórico-prática. Porto Alegre: Penso, 2018.

BALDEZ A. L. S.; DIESEL A.; MARTINS S. N. Os Princípios das Metodologias Ativas de Ensino: uma abordagem teórica. Revista Thema, v. 14, n. 1, p. 268-288, 2017.

BERBEL, N. A. N. As metodologias ativas e a promoção da autonomia de estudantes.

Semina: Ciências Sociais e Humanas, v. 32, n. 1, p. 25-40, 2011.

BERGMANN, J.; SAMS, A. Sala de Aula Invertida: uma metodologia ativa de aprendizagem. Rio de Janeiro: LTC, 2018.

IMBERNÓN, F. Formação continuada de professores. Porto Alegre: Artmed, 2010. INSTITUTO NACIONAL DE ESTUDOS E PESQUISAS EDUCACIONAIS - INEP. Índice de Desenvolvimento da Educação Básica - Ideb. Brasília, 2017.

KENSKI, V. M. A urgência de propostas inovadoras para a formação de professores para todos os níveis de ensino. Revista Diálogo Educacional, v. 15, n. 45, p. 423-441, jul, 2015.

MORÁN, J. M. Mudando a educação com metodologias ativas. In: Convergências Midiáticas, Educação e Cidadania: aproximações jovens. Coleção Mídias Contemporâneas, v. 2, n. 1, p. 15-33, 2015.

OLIVEIRA, C. L. Um apanhado teórico-conceitual sobre a pesquisa qualitativa: tipos, técnicas e características. Revista Travessias, 2009.

SANTAROSA, L. M. C.; CONFORTO, D. Formação de Professores: Construindo Cenários Inclusivos. Revista Novas Tecnologias na Educação (RENOTE), v. 8, n. 1, 2010.

SCHMITZ, E. X. S. Sala de Aula Invertida: uma abordagem para combinar metodologias ativas e engajar alunos no processo de ensino aprendizagem. 2016. 187 p. Dissertação (Mestrado em Tecnologias Educacionais em Rede) - Universidade Federal de Santa Maria, Santa Maria, 2016.

SOTA, M. S. Flipped learning as a path to personalization. In: MURPHY, M.; REDDING, S.; TWYMAN, J. Handbook on personalized learning for states, districts, and schools. Philadelphia: Center on Innovations in Learning, 2016, p. 73-87. 